\title{
1993: El Neo-socialismo pide la palabra
}

\author{
Francisco Javier Ibisate
}

\begin{abstract}
A lo largo del siglo- $X X$ hemos sido testigos dolientes de la coexistencia no-pacifica del capitalismo y socialismo. Al tinalizar el siglo se remodelan los sistemas con los epigrates de neoliberalismo y neosocialismo, siendo el primero quien se adjudica el derecho de ciudadania sobre el tercer mundo. En anterior publicación nos hemos preguntado si el neoliberalismo es una corrección o una reencarnación del liberalismo. Luis de Sebastián sostiene algo más sorpresivo: "el neoliberalismo una negación del liberalismo". Neoliberalismo es no-liberalismo. En resumen: distinto, pero el mismo darwinismo social de cara al tercer mundo; el neoliberalismo es la internacionalización del liberalismo nacional. Su evolución teórica e histórica queda reflejada en las siguientes citas bibliográficas. ${ }^{\prime}$
\end{abstract}

Algo distinto sucede con el neosocialismo luego del proceso de perestroika y auloevaluación. El neosocialismo es la negación de los "socialismos reales". Ya desde 1968 (invasión de Checoslovaquia) connotados socialistas, inicialmente delensores del modelo centralista soviético, giran su brújula de 180 grados: "ahora tenemos que analizar lo que es socialismo a partir de lo que no es socialismo". Con la publicación de Perestroika (1987) los residentes de los socialismos reales

1. Luis de Sebastián: "El neoliberalismo una negación del liberalismo". Realidad Económica-Social, 1989; N²11; pp. 419-436.

"Solidaridad y mercado". ECA, 1992; N² 527; pp. 757-700.

Ibisale FCo. Javier: "El neoliberalismo no es un dogma de len. Realidad Económico-Social. 1992; N² 29; pp.. 485-516. 
autoevalúan los setenta afios de experiencia del modelo centralista en "la mesa redonda de hisloriadores soviéticos" (Moscú, 1988), en el foro de Barcelona (1988), en el foro de Moscú (1989), en el coloquio de La Sorbona-Paris (1990) y en los sucesivos programas de reestructuración económica (1987-1991). En este proceso de aulocrítica se integran pensadores-escritores tachados de "revisionistas" dentro del mismo bloque, asl como represenlantes de movimientos sindicalistas y socialdemocratas calificados como "social-Iraidores" desde 1919 por quienes luego desnaturalizarían al verdadero socialismo. A la par de estos encuentros emana una abundante literatura, sobre todo al interior del conlinente europeo, donde a lo largo del presente siglo han coexistido distintas interpretaciones y modelaciones del gran movimiento socialista (incluidas las escuelas de ensefianza social de la Iglesia Católica y Protestante) en reacción a los efeclos deshumanizantes del capitalismo decimonónico.

El hecho de que una de esas alternativas se impusiera por razones históricas, monopolizando y posteriormente destigurando la imagen del verdadero socialismo, ha dado lugar a dos posturas teorico-históricas. Los teóricos y prácticos del neoliberalismo con el fin de mantener su hegemonia mundial y olvidando sus propias crisis, tratan de confundir e identilicar el caos del socialismo-reak con el término linal de cualquier alternativa socialista en lo político y en lo económico. Se cierran asi los ojos a los grandes avances sociales logrados en la Europa occidental que han hecho posible el mismo auge económico de esos paises. De acuerdo a esta leclura parcial y sesgada del siglo- $X X$ se reducen las alternativas político-económicas a un sólo modelo neoliberal que concentra, o parece reducir el bienestar a los grandes equilibrios de la conlabilidad nacional. Tal es el escenario oficial de nuestro país. La otra posición más realista e histórica, es la de todos aquellos que, viviendo en un mundo interdependiente y más comunicado, reactualizan los valores socialistas como la respuesta a la profunda crisis económica y civica, efecto de la "guerra-fría", del crecimiento mundial de la pobreza y de la toma de conciencia de lanto derecho humano irrespetado. El néosocialismotes la vuelta al hombre, a la democracia trente a la mercadocracia. Por esta razón dedicamos parte de este arlículo a comentar una reciente macroencuesla europea.

\section{La autocricla: dlsıntos pero parecldos}

En anteriores arlículos hemos recogido suficientes testimonios de la autocrítica realizada en esos loros y coloquios arriba mencionados que utilizamos más adelante. ${ }^{2}$ Los bruscos cambios y los análisis realizados

2. Ibisale Fco. Javier: "Los neosocialismos reales hacen su propia autocrítica". ECA, 1991; № 513-514; pp. 675-710. 
en la Europa del Este encuentran una respuesla hislórica en nuestros movimienlos de izquierda, como lo muestran los siguientes documenlos.

Es posible resumir la aulocrílica socialista en las reflexiones que nos ha dejado M. Gorbachov, a raiz del frustrado golpe de eslado de agoslo 1991, lidereado por los radicales del partido comunisla. "Yo soy una de esas personas que nunca ocultan sus convicciones. Soy parlidario confirmado de la idea de socialismo. Es una idea que ha venido abriéndose camino por sí misma durante varios siglos. Tiene muchos seguidores y éstos han presidido los gobiernos de numerosos Eslados. Exislen varias ramas del movimienlo socialisla porque no es una especie de "modelo al que deba adecuarse la sociedad. No, es una idea, precisamenle una idea que abarca valores desarrollados en el curso de la búsqueda de una sociedad más justa y un mundo mejor. Es una idea que extrae energia de muchos hallazgos del crislianismo y de olras tendencias filosóficas. La idea de socialización está presente en muchos movimientos políticos y sociales. Yo me considero a mí mismo un demócrala y baso mi pensamiento en que la idea socialista sin democracia y sin una solución correcla y fiable de los problemas sociales no es posible. En consecuencia creo que debemos reconocer que fue el género de socialismo que teniamos en nuestro pais lo que demostró ser un fracaso, y no la idea socialista en si. La pregunla se plantea algunas veces: ¿fue la Revolución de Oclubre una calástrole, o fue después de todo una genuina revolución? Comprendo el motivo de que esta cuestión resucite: es debido a que los resullados históricos de la Revolución de Octubre no fueron aquellos con los que contaban las personas que hicieron la revolución. Dichos resullados históricos no fueron los resultados de llevar a término las "ideas de oclubre", una auténtica revolución del pueblo; lo fueron de la forzada introducción del modelo estalinista de sociedad. Uno no debe conlundir ambas cosas. En lo que concierne a mis punlos de vista, a lo largo de los años lo he hecho lodo para poner fin al eslalinismo. Sin eslo no tiene senlido pensar siquiera en llevar a la realidad la idea socialista. La vida en cada país debe ser la obra de su propia gente. Constituye hoy nuesiro deber entender y desarrollar los procesos de democralización en tudas las esferas. Pienso que lodo ello viene a ser como un movimiento hacia una mayor justicia para el individuo y la afirmación de sus derechos y libertades y de los derechos y libertades de los pueblos. $Y$ que es cierlamente un avance en la dirección de realizar la idea socialista. Tal es mi interpretación del problema"s

"Del golpe de agosto-1991 a los programas de ajuste estruclural en la URSS". Realidad-Económico-Social, 1991; N²3; pp. 647-696.

3. M. Gorbachov: "El golpe de agoslo: la verdad y sus consecuencias". E. Diana, México, 1992; pp. 57-60. 
Tal vez esta cita pueda sonar como el canlo del cisne de un hombre que cambió la hisloria y a quien la historia le debe eslar agradecida. De momento M.Gorbachov ha sido defenestrado por los lideres $y$ contralideres de una república, que ni es unión ni es nación, que ni es plan ni es mercado y que lo único que enirenta es un futuro imprevisible. No ha tracasado la "perestroika", en cuanto reforma-revolución, sino que esłán fracasando quienes, por posición u oposición, traban la marcha de los irremediables necesario.

Lo importante para nuestro pequeño occidente es que también entre nosotros crece el número de pensadores de izquierda que entran en un proceso de "pereslroika". Con fecha de sepliembre-1992 Juan Medrano publica en ECA un artículo titulado "Revolución Democrática: tesis para la estrategia del FMLN". Los edilores resumen asi el pensamiento del autor". El cambio de las condiciones nacional e internacional y de las formas de lucha exigen un cambio en el pensamiento de la izquierda revolucionaria. Es necesario enriquecer o romper los esquemas menlales en torno a los conceptos de poder, revolución y hegemonía, integrando en el discurso político revolucionario los conceplos de democracia, mercado, propiedad privada social y concertación. Las tesis siguientes tienen la pretensión de ser un aporte en esta dirección". ${ }^{4}$

Un mes más tarde Joaquin Villalobos publica, en ochenta páginas, un esclarecedor manual del nuevo pensamiento revolucionario, cuya lectura recomendamos con la mejor intención en este año preelecloral y de reconciliación. "Vivimos un momento de ruplura en la historia universal. Este momento comenzó hace veinte anoos cuando nacieron las corrienles revolucionarias que cuestionaron al socialismo burocrálico eslatista y al liberalismo capilalista salvaje. La coincidencia entre la Primavera de Praga en Checoeslovaquia y los acontecimientos de mayor del 68 en París no fueron casualidad, como tampoco fue casualidad la coincidencia en el inicio de la guerra en El Salvador con la crisis de Polonia y que el día que se tirmaba la paz en El Salvador terminaba su existencia la Unión Soviética. Se trata de dos hechos revolucionarios de enorme Iranscendencia histórica. Se derrumba el socialismo estatista y era el principio del fin del capitalismo proligárgico, dependienle y anlidemodrático de El Salvador, que en su última etapa adquirió formas muy solisticadas. La bandera de la democracia pasa a manos revolucionarias. El FMLN es parte del proceso de gestación de un nuevo pensamienlo revolucionario y una nueva izquierda. Esta es una hora de prueba para los revolucionarios, es hora de cambios, de romper dogmas,

4. Medrano Juan Ramón: "Revolución democrálica: tesis para la estrategia del FMLN". ECA; 1992; Ne 527; pp. 6723-740. 
tabúes, ataduras teóricas y lalsas premisas morales. Es momenlo de avanzar equivocándose en los esfuerzos por consiruir un nuevo pensamiento, en vez de hundirse en los viejos errores o quedarse paralizado por los miedos a equivocarse. Es momenlo de propueslas para aprovechar el marco altamente positivo para la revolución".

Esta revolución en la izquierda se venía gestando desde hace un tiempo como lo dejó escrilo el mismo Joaquín Villalobos a inicios de 1989 en un artículo, cuyo acápite segundo se titula: "Un proyecto revolu. cionario abierto, pluralista y democrático: ¿propaganda o nueva realidad polílica?"* No es ni debe ser la intención de estas cilas al identificar neo-socialismo con neo-FMLN, a modo de propaganda de determinada filiación política, aunque nos alegra esta evolución de su pensamiento político-económico. Sin embargo, el papel de la universidad es servir al universo de la sociedad. Se trala ante todo de quilar miedos congénitos a cierlas expresiones aclarando su conlenido. Digamos que el socialismo democrático es, por principio, parlamenlario y pluripartidista como condición de la democracia politica. El socialismo democrálico integra en su modelo económico el mercado competitivo, la función clave empresarial, el sistema de precios, la calidad y los coslos de producción, la propiedad privada social, y no defiende el igualitarismo de ingresos, si bien propicia la mejor seguridad social. El socialismo democrálico es un modelo que busca la democracia política y económica como componentes de la democracia a secas. Por esta razón el socialismo democrático es una ideologla y una estrucluración de la sociedad equidislante del socialismo estatista de ordeno y mando y del neoliberalismo monopolisla de mando y ordeno.

He aqui un dato aleccionador: en enero de 1990 se realiza una macroencuesla en nueve palses del Esle-Oeste europeo (R.F.A., Espaha, Francia, Reino Unido, Hungria, Polonia, UASS). Como enseguida vamos a regresar sobre las grandes respueslas de la encuesta, de momento sólo indicamos que el $57 \%$ de los soviéticos votaron a favor del "socialismo democrálico": sin lugar a dudas en esta mayoritaria respuesla estaba inlluyendo la Perestroika de M.Gorbachev con su estribillo: "más socialismo más democracia". Entrecruzamos este dato estadístico con otro hecho histórico algo relevanle.

En agosto de 1991 los adversarios de las relormas político-económi-

5. Villalobos Joaquin: "Una revolución en la izquierda para una revolución democrática". E. Arcoiris. San Salvador; 1992; p. 5.

6. Idem: "Perspectivas de victoria y proyecto revolucionario. ECA, 1989; N" 483; pp. 36-51. 
cas de la URSS organizan un golpe de estado contra M. Gorbachov. ¿Quiénes son y a quiénes representan estos ocho golpislas? No es un sólo grupo, sino la simbiósis de la trilogía peremnemente privilegiada. Entre los golpislas tenemos representantes de la cúpula del partido, auspados por el mismo Gorbachov: G. Yanayev Vicepresidente, B. Pugo Ministro del Interior, V. Pavlov Primer Ministro; representanles de la jerarquia militar y policial: D. Yazov Minislro de Defensa, V. Kriuchov Presidenle de la KGB; representanles de la aristocracia industrial militar: Oleg Blaknov, A. Tiziakov y V. Slarodubisev. Esta era la trilogía privilegiada en el socialismo centralista: partido, jerarquia militar y aristocracia económica. La pregunta es la siguiente antes y después de los Acuerdos de Paz: ¿no ha sido esla misma trilogía (partido-ejército-aristocracia económica) la que ha Iroquelado nuestro modelo social sin mayor espacio a la democracia política y económica?. Dos regímenes diferentes se emparentan en lo que son iguales. Por ello el socialismo democrático tiene algo que decir en 1993...

Para desfigurar el parenlesco político se ha dicho y se seguirá diciendo en 1993 que el socialismo es sinónimo de planificación centralisla y que la historia ha demostrado suficienlemente el desastre de la planiticación; mientras que el neoliberalismo se apoya en el mercado compelilivo gestor del crecimiento nacional. En realidad la hisloria es muy dislinla y la aulocrítica nos dice que en el socialismo real las iniciales técnicas de planificación (que influirian en la planificación económica de Europa occidental) derivaron rápidamente a una dictadura política e imperialización económica, haciendo de las empresas simples unidades de producción o culto a la "producción-bruta" que critica Perestroika. La trilogía privilegiada se opuso dentro y fuera de a URSS a todos los intentos de reformas económicas, de la misma manera que se ha opuesto a los últimos programas de transformación económica de Sthalin, Abalkin, Aganbergian, Yaulinsky... Por lo que hace a nuestro modelo neoliberal no se puede llamar mercado competitivo y democrático aquel donde vuelve a aparecer la concentración del capilal o de la administración de la producción, y donde las grandes demandas sociales de educación, salud-nutrición, vivienda... se adscriben como programas subsidiarios para el Estado, en la segunda parte del Plan Económico-Social. Las recientes encuestas del IUDOP han emilido un volo negativo al modelo. (Proceso, № 540).

Hay un argumento que nuestros neoliberales occidentales no se atreven a airear para no ser sorprendidos por varias "comisiones de la verdad". Se ha acusado a la ideología del socialismo-real por su aleísmo oficial y su cruenla persecución religiosa. El Papa Juan Pablo-II hace relerencia explicita a este manchón negro del comunismo este-europeo 
en su reciente encíclica (mayo-1991), conmemorando el centenario de la Rerum Novanum. En un comenlario a esa enciclica deciamos que en el capítulo-III hay párralo del Papa polaco que puede leerse en clave comunista y en clave capitalista: "Mientras en unión con loda la Iglesia doy gracias a Dios por el teslimonio, en ocasiones heroico, que han dado no pocos pastores, comunidades cristianas enteras, fieles en particular y hombres de buena voluntad en tan dificiles circunstancias, le pedimos que sostenga los esluerzos de lodos para consiruir un fuluro mejor". ( $\mathrm{N}^{2}$ 34) Y afiadiamos: "En la Europa del Esle el párralo se lee en clave de la larga persecución comunista a la iglesia del silencio, recordando los nombres de los Minchenty, Wiszinsky... y lantas iglesias y tieles perseguidos. En nuestro oeste latino y centroamericano contamos con la corte de mártires y confesores presidida por Mons. Romero y la legión de perseguidos, lorturados, exiliados por querer ser la voz de los sin voz. Mucho se ha hablado y escrito sobre el ateismo teórico y a veces lanático de los regímenes comunistas, y ello es cierto. Pero lambién el capitalismo practica el ateismo real al encerrarse en su materialismo económico, donde Dios ni es fin ni es medio y donde si no se le alaca abierlamente es porque no se piensa en Dios ni para negarlo. También existen, de acuerdo a las palabras de ambos Papas (León-XIII y Juan Pablo II) los ateos por omisión, que ponen a Dios en un cielo ultraterreno y se escandalizan y persiguen a la Iglesia cuando se preocupa por montar el Reino de Dios en la tierra. Si sistemas opueslos son similarmente arreligiosos y ateos nos resulta inconsecuente aceplar que el fracaso de los unos signifique la aprobación de los olros porque "no sólo de pan vive el hombre".

A este comentario de hace casi dos anos anadiriamos ahora que los lideres oficiales del neoliberalismo-ARENA pretenden silenciar esta cruenta persecución religiosa (en nombre de Dios, la Constilución y el anticomunismo) con una falseada opción cristiana de "perdón y olvido". Con loda razón el Dr. Boutros-Boutros Ghali (ONU), en su discurso del 15 de diciembre 1992, insistió en que se descubra la verdad; al iniciar el nuevo ano crecen las prolestas porque la Presidencia de la República da muestras patentes de todo lo contrario. No se puede olvidar -mienIras no se haga justicia a la verdad-que el neoliberalismo salvadoreño ha sido persistente perseguidor de inocentes y de la religión comprometida por una democracia social. De nada vale que se invoque a Dios cuando se persigue y mata a tantos hombres de Dios. Desde este ámbito religioso no aceplamos un neoliberalismo económico que piensa más en el crecimiento de las mercancias que en la dignidad y desarrollo de lodos los hombres. Era de esperar que la IV" Conferencia Episcopal Lalinoamericana, reunida en Santo Domingo (octubre-1992) se muestre 
adversa a las consecuencias sociales del neoliberalismo económico. Es trislemente lógico que los financistas del neoliberalismo norleño se esfuercen por descatolizar al pueblo latinoamericano con la invasión de sectas fundamentalistas opuestas a los movimientos de liberación cristiana.

El Papa Juan Pablo-II, en su mensaje para la celebración de la Jornada Mundial de la Paz (1-enero-1993) cuyo tílulo es: "Si quieres la Paz sal al encuentro del pobre", nos dice: "La reciente conferencia Episcopal Latinoamericana ... ha invilado de manera apremiante a los fieles y a cuantos aman la justicia y el bien a servir la causa del hombre sin soslayar ninguna de sus exigencias más prolundas. Los obispos han recordado la gran misión que debe coordinar los esfuerzos de todos: delender la dignidad de la persona, compromelerse en una distribución equitativa de los bienes, promover de manera armónica y solidaria una sociedad donde cada uno se sienta acogido y amado... en efecto, decir paz es decir mucho más que la simple ausencia de guerras; es pedir una situación de auténtico respeto a la dignidad y a los derechos de cada ser humano, que le permita realizarse en plenilud. La explolación de los débiles, las preocupantes zonas de miseria y las desigualdades sociales constituyen otros tantos obstáculos y rémoras para que se produzcan las condiciones estables para una auténtica paz" (pp. 4-5).

Estas palabras del Papa suenan más a socialismo democrático que a neoliberalismo capilalista: "Si quieres la paz sal al encuentro del pobre" es el mensaje para 1993. Para responder a las preguntas de los periodistas hemos evaluado el pasado año-1992 desde los logros y délicils del producto nacional, de la balanza comercial del presupuesto y de la inflación. El modelo olicial pone mucho énfasis en los éxilos logrados en eslas variables macroeconómicas para mostrar que él es la ruta de salvación. Cuando las macrovariables no tienen éxito, por ejemplo los délicits en la balanza comercial y presupuesto eslalal, se deduce que los fallos se deben a no haber aplicado bien el modelo: hacen falta más impuestos y más exportaciones. Cuando alguna macrovariable da sefíales de recuperación, por ejemplo el PIB real incremento en $4.5 \%$, invenIan un número imaginario como seria un incremento del $2.1 \%$ en el percápila, dejando en el tintero que con una inflación del $20 \%$ lo que en realidad ha habido es una translerencia de ingresos fijos de asalariadosjubilados hacia los grandes productores-vendedores. Por esta razón los economistas deben contronlar los datos para evitar una mala publicidad en vísperas de las elecciones presidenciales. No signilica esto que dudernos de que pueda haber crecimiento dada la gran laboriosidad del pueblo salvadoreno, sino que buscamos que el crecimiento se transiorme en equidistribución y se haga acompanar de los procesos democráti- 
cos paclados en los Acuerdos de Paz. Además de cifras macroeconómicas hay otros problemas a nivel nacional e internacional.

Nos asomamos breve y parcialmente al mundo internacional donde, en primer lugar, se advierte una prolongada crisis económica luego de la llamada "guerra-fría" o paz-armada. Sin duda, como una consecuencia de la guerra fría bulle una crisis de valores o antivalores civicos, políticos, nacionalismos, xenolobias, donde el fenómeno de las lagunas de pobreza, de marginación étnica y de creciente incertidumbre angustia a buena parte del mundo. Por esta razón creemos conveniente asomarnos a esos problemas y a las respuestas que se encuestan como salida a los problemas. Si allá se habla de neoliberalismo, también se vota por el socialismo democrático. Luego de esta incursión en el orden mundial podemos regresar a nuestro-1993 como año de los Acuerdos de Paz.

\section{Conservadores en lo económico, socialdemócratas en lo demás.}

Pareceria que con el dernmbe de los socialismos reales la Europa del Este y Oesle unilicarían su opción por una economía de mercado que rescalara a los exsocialistas en su retraso técnico-productivo amarrándolos a la potenle locomolora occidenlal. Parecería que los propios occidentales renunciarian a las variaciones y supervivencias socialistas adoptadas luego de la gran crisis mundial-1930. La verdad es que ninguna de eslas hipólesis se ha cumplido; nuevos problemas surgen bruscamente, que salen del radar de lo económico y que no se resuelven con uno u otro de sus modelos. En primer lugar, si en el Este ha habido un derrumbe económico y político, en el Oeste (integrando aqui a los Estados Unidos) se está atravesando una seria recesión económica con el recrudecimiento del déficit, el desempleo y la inflación, sumado ello a convulsiones sociales, rebrotes de nacionalismo (movimiento neonazi y otros), xenolobia beligerante, aluviones de inmigrantes e inseguridad en amplias capas de la población. La esperada unidad europea no sólo encuentra algunas resistencias an Maastricht para la unión monetaria, sino a nivel nacional (URSS, Yugoslavia, Checoeslovaquia...) y conlinenlal, que dilicullan la esperada recuperación del Este europeo. Por lo que hace a la primera potencia militar, los EE.UU. los tilulares afirman que "La economia de los EEUU sulre la crisis más profunda y larga desde los años Ireinla".

De este escenario concluimos que la crisis económica, aunque con distinta intensidad, se eslá dando no sólo en uno de los sistemas económicos de manera que haya que optar a ojos ciegas por el que se dice vencedor, que aparte de la recesión y proteccionismo económicos encuentra otros problemas que vamos a comentar. Esta crisis económica 
occidental no es, de momenlo, el mejor escenario para asentar el eje de nuestra economía en el mar abierlo del comercio inlernacional, sin antes fortalecer nuestra propia inlegración geográfica, como lo están haciendo los europeos y los americanos del norle. Algo muy imporlante es que Europa vuelve a buscar un nuevo modelo de producción y de convivencia social, y al encueslar a sus ciudadanos rescala valores antiguos socialistas. Porque to que llamamos neosocialismo comprende un conjunto de corrientes sociales muy distintas del socialismo-real y tanto 0 más anliguas que aquel. Ese neosocialismo tiene algo que decirnos para $1993 \ldots$

\subsection{La encuesta macroeuropea}

Ya hicimos mención de la macroencuesla pasada en enero de 1990 en ocho países del Este-Oeste europeo, cuyos resultados son tema de agenda del coloquio de La Sorbona, París, febrero de 1990. El escenario histórico europeo presenta bastantes semejanzas con el nuestro: fin de una guerra, en su caso guerra tria, caída de los socialismos reales y búsqueda de algo nuevo impredecible. Por el otro lado, qué modelo económico y social propiciaria la mejor unión europea de este y aquel lado del muro de Berlín. Al querer armonizar el mosaico europeo no es lácil identificar a cada pais con determinado modelo económico porque cada historia está hecha de supervivencias del pasado y de previvencias del fuluro; la sucesión e inlegración de gobiernos nacidos del pluripartidismo han geslado unos complejos regimenes socio-económicos. El hecho de que se realice una macroencuesla y que sus resullados sean debatidos en el coloquio de La Sorbona por Ireinta exponentes de esas ocho naciones represenla, a la vez, un cuestionamiento del siglo-XX que termina y una expeclativa para el naciente siglo $X X-I$. En realidad esta encuesta europea es más que europea y nos sentimos interpelados por las mismas preguntas y opciones. No hay lugar para trasladar loda las pregunlas, cuyo resumen y comentario aparecen en Realidad Económica y Social, $\mathrm{N}^{2} 13,1990$, pp. 28-43. Para nuestro propósilo nos centramos en algunas preguntas y sus comentarios.

Se solicita a los encuestados especilicar más en detalle las opciones económicas y políticas: "Digame si cada una de las palabras que le voy a citar son para usted básicamente positivas o básicamente negativas. Las palabras son: liberalismo, comunismo, socialismo democrático, capitalismo, socialdemocracia". La respuesta mayoritaria enuncia: "ni comunismo ni capitalismo". Resulta ilustrativo que incluso en paises donde el partido comunista habia jugado un papel importante, Ilalia, Francia..., salga ampliamente malparado: $60 \%$ y $79 \%$ respectivamente. Semejante es la suerte del capilalismo, considerado como negativo en la mayoría 
de paises, con porcentajes que oscilan entre $40 \%$ (RFA) y el $52 \%$ (Francia, Italia). La excepción es Polonia, con $42 \%$ a favor, porque 10 contrario de "lo soviético" tiene que ser mejor. Los británicos lo juzgan positivo en un $41 \%$, trente al $37 \%$ que lo calíican como negalivo. Ya dijimos que los soviéticos aspiran, en un $57 \%$, por un socialismo democrático que no responde a una realidad existente sino a los ideales de Perestroika.

El "liberalismo", como opción política o apertura a las libertades política, es positivamente apreciado por el conjunto de los paises encueslados. Se trata del liberalismo político pues quienes valoran más positivamente el concepto de liberalismo coinciden normalmente con quienes han valorado más negativamente al capilalismo. Siguiendo y resumiendo el conjunto de las respuestas la principal línea opcional enuncia: "conservadores en lo económico, socialdemócratas en los demás". Como los encuestados ponderan la historia de cada pais y no un determinado gobierno, se calalogan como principales paises socialdemócratas la República Federal Alemana, Francia y Suecia; pareceria que la idea de Socialdemocracia va unida "a la abundante generación de riqueza y a la equitaliva distribución de la misma". Se deduce de la encuesla que los gobiernos conservadores, incluyendo la Alemania de Khöl, llevarian la ventaja en la gestión económica, mientras que la socialdemocracia obliene mejores resultados en el área de los asuntos sociales y derechos civiles. La encuesla sigue preguntando, ¿cuáles serian para usted las caracleristicas más represenlativas de la socialdemocracia? (Esta pregunta no se pasó en la encuesta de la URSS). El resto de paises preterencian las siguientes caraclerísticas: seguridad o prolección social para lodos; la reducción de las desigualdades; la participación de los asalariados en la gestión de las empresas. Señalamos que "el igualitarismo y las elevadas cargas sociales" no son identilicados entre los rasgos propuestos; sólo los húngaros y los polacos consideran "un alto nivel de vida" como caracteristica de la socialdemocracia, que en ambos paises obtiene más votos que el modelo liberal-capilalista. (Ibidem, 1990, pp. 28-33 y ECA, 1991; pp. 693).

"Conservadores en lo económico, socialdemócratas en lo demás". ¿Se trata de un nuevo modelo o se trata de alianzar una opción del pasado? Para los países del Este se Irata de un nuevo modelo, sea que preferencien la socialdemocracia o el socialismo democrático. Para los paises del Oeste se trata de alianzar, reacomodando al tiempo presente las experiencias ganadas en el último medio siglo de economias sociales; por lo lanto se trata de identificar, ante el Este-Oeste, los rasgos esenciales tanto de la socialdemocracia como de otros movimientos socialistas similares. Ya en el foro de Barcelona (1988) se habian enlatizado las marcadas diferencias entre los socialismos reales y el resto de 
corrientes socialistas, subiendo la crítica desde el régimen estalinista hasta la propia imagen de Lenín. (ECA; 1991; pp. 687-691). En el coloquio de La Sorbona (1990) se reivindican los objetivos de la socialdemocracia Irente a los socialismos reales. Por supuesto, no se trata aqui de reducir las opciones a plan y mercado, porque toda economía necesita de plan y mercado; negar uno de estos componentes es negarse a "hacer economias". Todo un conjunto de problemas civico-nacionales exigen algo más de lo que reductivamente llamamos plan y mercado. Un ejemplo, los Acuerdos de Paz.

El Primer Ministro del país anfitrión, Michel Rocard inaugura el coloquio... "Los comunislas en el Oeste, y todavía más en el Este, quisieron apropiarse de la noción misma de socialismo, aunque lo que en el Oesle llamamos socialismo quiere decir socialdemocracia, sociedad pluralista, economía compeliliva y diversificada, prolección social; y lo que se presentaba en el Este como socialismo signilica para nosotros comunismo. Es pues importante eslablecer la veracidad de las palabras... Desde el golpe de estado bolchevique, los principales dirigentes de la lla Internacional, León Blum, Karl Kausdtky y tantos otros dijeron lo esencial: que el voluntarismo de Lenín sólo podía conducir a una dictadura duradera sobre el proletariado; que solo la democracia politica permite conocer la voluntad popular; que la democracia no puede ser sólo un medio, sino un fin. La oposición que de ahí derivó entre el comunismo y el socialismo fue irreductible en el fondo" (Ibidem; pp. 689-691).

Con el deseo de ahondar brevemente en eslos conceptos se combinan, a modo de pregunta-respuesta, sendas intervenciones de dos economistas soviélicos detensores de la perestroika y que renunciaron al partido en 1991. Andrei :Grachov expone y pregunla: "Venimos del pais del socialismo real, que ha sido a veces un socialismo irreal o incluso más que real, ya que albergaba la ambición por encima de la realidad y del realismo. Hay que decir que este socialismo ha Iracasado. Lo decimos entre nosotros y lo reconocemos anle usledes. Pero una cuestión permanece abierta: ¿este fracaso es del socialismo en cuanto tal, como ideal, como ambición, como orientación de la evolución de la sociedad, de la humanidad, o se trata de un Iracaso particular, preciso, desdichado, condicionado por las condiciones particulares de Rusia...?" La pregunta quiere ser respondida por N. Petrakov, colaborador del Programa de los $\mathbf{5 0 0}$ dias de S. Shatalin: "El socialismo es una concepción del mundo, un concepto muy amplio de valor de la personalidad; es una visión de la sociedad que da protección social a la persona, que no sólo protege su libertad, sino que le da unas garanlias de satistacción al margen de la aportación del individuo al desarrollo económico del pais... Por eso yo pienso que el mercado, como forma de penelración de la 
democracia socialisla en la economía es nuestra única posibilidad. Es intercambio democrático lo que hace lalla. El mercado y el socialismo son dos conceplos compalibles, y yo considero que muchas ideas socialistas no pueden realizarse fuera del mercado".

En los escritos recientemente publicados por representantes del FMNL, a los que hicimos referencia en la parte introductoria, encontramos similar evolución del pensamiento socialisla; sin duda estos documentos evalan este último testimonio de quien luera inspirador de la Primavera de Praga (1268); en su libro, "Para una democracia económica humana", Ota Sik critica a la burocracia del partido: "...En la cúspide se va desarrollando una burocracia a la detensiva contra loda crítica que, en un modelo más descentralizado, pudiera venir del mercado, del sistema de precios, de la competencia empresarial. Como se sienten incompelentes se cierran ante cualquier discusión y se refugian en medio de trabas burocráticas. Se cubren con una mala entendida ortodoxia, que ellos mismos crean, condenando al mercado, a los precios y a la competencia empresarial como mecanismos antisocialistas. Deforman el mismo concepto de propiedad, confundiendo la propiedad social con la propiedad siempre creciente del Estado y extraido de la plusvalia del trabajo. Tienen miedo a cuanlo les puede hacer competencia y lienen miedo al pueblo, gracias al cual viven. Cada vez más dejan de pensar y de creer en el pueblo, y cada vez más el pueblo deja de creer en el partido..." (ECA, 1991; pp. 685-687).

La razón para Irasladar algunos entre los múltiples testimonios de esle coloquio es doble: se trata de recuperar la imagen desfigurada de lo que es socialismo. En segundo lugar que este neosocialismo aparece en los movimientos revolucionarios ("Revolución en la izquierda") como el componente inspirador de "la revolución democrática". En el capitulo primero, "Socialismo Democrático" de Joaquín Villalobos podemos encontrar las mismas reflexiones. "No basta decir que queremos un socialismo distinto al que se derrumbó. Recordemos que la lógica que prevaleció durante la guerra Iria fue la división del mundo en dos bloques: capitalismo y socialismo. Conforme a este criterio, cualquier otro modelo que no se atuviera a los patrones del socialismo de la Europa del Este (socialismo-real) no fue considerado como socialismo. Para que un modelo fuera considerado como tal habia que eliminar la propiedad privada, mantener el poder de forma permanenle a partir de un estado centralizado y sin oposición política alguna... Quedarse únicamente en el rechazo de lo que se derrumbó no tiene ningún sentido. Es necesario delinir lo nuevo. Si bien la meta debe ser siempre una ulopia, ésla debe ser claramente definida, razonable y lógica. 
...Al ideal del socialismo se integran sin contraposición y como inherentes a ésle, los conceplos de democracia y mercado. La convivencia y la competencia con otros sectores políticos es fundamental para desarrollar y lortalecer la fuerza que conduce al proceso. Sin oposición sería, en última instancia, siempre débil. A su vez, el mercado es el terreno donde se pone a prueba la competitividad de la propiedad social, que no puede ni debe depender del estado. Estos conceplos, mercado y democraca, son el alma del debate entre los revolucionarios. Son el punto donde se deslindan las nuevas posiciones. La propiedad social no puede ser eficienle, ni desarrollar la sociedad, ni llevar bienestar y riqueza a los trabajadores si no entra al mercado. Sin mercado, la propiedad social puede hacer justicia temporal, pero no conduce al desarrollo, ni genera riqueza... ...El mercado no es contradictorio con el socialismo. Su supresión es antidialéclica. Suprimirlo es llevar a la sociedad al alraso. En un sistema sin mercado los precios de los bienes son decididos burocrálicamente y se genera un paternalismo que deforma el poder de la fuerza de trabajo. Esto redunda en aberraciones económicas que a la larga producen miseria... El socialismo real llevó la negación del mercado al absurdo, regresando sus economias al trueque. Queriendo evitar el enriquecimiento creó mecanismos burocrálicos ineficientes para la distribución de las mercancías. Este sistema impactó directamente en la calidad de los productos y por lo tanto en el desarrollo de las fuerzas productivas, siendo en este aspecto superado enormemente por las economias de mercado. En la actualidad se ha confundido mercado con capitalismo y eslatismo con socialismo... El capitalismo salvaje idolatra al mercado y lo coloca por encima de todo. Niega la juslicia social o la deja reducida a simple caridad. El socialismo real, en un intento de hacer justicia social, negó el mercado de manera absoluta, lo cual hizo retroceder las sociedades a primitivas economias de inueque... No puede haber lo uno sin lo otro. Socialismo autoritario es opresión y atraso. Democracia capitalista es miseria para las mayorias y opulencia para pocos; por lo tanto no es democracia real. Ser socialista es ser profundamente democrálico; ser democrático es ser prolundamente socialisla" (pp. 9-13).

Esla superposición de testimonios y de aclaraciones ayuda a esclarecer to que en Europa se ha enlendido por socialismo democrático y también la evolución o revolución del pensamiento de nuestros movimientos de izquierda. Tal vez estas últimas declaraciones podrán sorprender, poner en guardia o Iranquilizar de acuerdo a la ideología o posición de quien las escuche. Con la acumulación de texlos o declaraciones se Irala de mosirar que esle género de socialismo puede dar respuestas adecuadas a la crisis polílica y económica aún persistente a 
nivel mundial. Tal vez nos puedan parecer alarmislas algunos titulares de los medios de comunicación: "El mundo sin la URSS y sin guerra tría vive la peor crisis desde la gran depresión de los años treinta". (EI Pais, $27-10-92 ;$ p. 3).

\subsection{Crisis económica, crisis política}

El orden no significa relación de causa y eleclo sino un proceso de retroalimentación activa. Comenzamos por una macrovisión económica, trasladando algunos de los titulares, en mayúsculas, del Boletín del Fondo Monetario Internacional-1992. Para mayores delalles el leclor podrá acudir al bolelín quincenal indicado. "Sigue empeorando la economia de lo que fue la URSS" $(13,1,92)$. "Recetas de los economislas en pos de la recuperación mundial" $(27,1,92)$. "Singular desafío económico se plantea en los países del Esle" $(10,2,92)$. "El déficit presupuestario de los Estados Unidos llegaría a los $\$ 352.000$ millones" $(24,2,92)$. "La reforma fiscal en Europa orienlal" (9, 3, 92). "La economia mundial sulre enormes cambios que plantean graves problemas" $(23,3,92)$. "Japón, potencia económica, con responsabilidades mundiales" $(6,4,92)$. "La Iransiormación de la antigua UASS es a la vez un reto y una oportunidad" $(4,5,92)$. "Determinación de respaldar el programa de reforma de Rusia" $(10,5,92)$; "El comercio mundial registró el crecimiento más pequeño desde 1983 " $(20,5,92)$. "El crecimienlo de la economia mundial sería del $1.5 \%$ en 1992" $(1,6,92)$. "En opinión del BIRF la protección ambiental es esencial para el desarrollo" $(15,6,92)$. "Conferencia FMI/BIRF: expertos examinan la caída del produclo en Europa oriental" $(13,7,92)$. "La hiperinflación en las antiguas economias de planificación central" $(10,8,92)$. "Estudio de la OCDE prevé un aumento del desempleo en 1992" $(24,8,92)$. "Pronunciada desaceleración del comercio mundial en 1991" $(28,10,92)$. "Es necesario reforzar medidas que fomenten la recuperación económica mundial". "La interdependencia mundial planlea problemas y oportunidades". $(18,11,92)$. "Los mecanismos monelarios deben lomentar la estabilidad de precios" $(16,11,92) \ldots$

- Esle breve recorrido de los grandes titulares muestra que después de la guerra fria, y quizás a causa de la misma, el mundo del Este sobre todo y también el del Oeste están atravesando una crisis económica sin que aún se prevean los signos de recuperación. Yendo de lo general a lo más particular, el déficit, el paro y la inflación crecen en la mayoría de los paises desarrollados. El Consejo de Asesores Económicos de Alemania, llamados los "cinco sabios", pronostican un crecimienlo cero para el primer semestre de 1993 (otros esperan un crecimiento del $0.5 \%$ ), luego de que en 1992 la economia creció sólo en 1.5\%, según las últimas previsiones. La inflación, un problema que los alemanes occidenla- 
les habian casi olvidado, se elevó en $4 \%$ en 1992; pero el problema más serio es el paro, que alcanza los 3.43 millones de desempleados. Los cinco sabios recomiendan reducir los aumentos de salarios al incremento de la producción. La "locomolora de Europa" se ve frenada en su esfuerzo por sacar a flote y privalizar las empresas de la zona oriental, además de los enormes gastos por recomponer el deterioro ecológico de esa zona. A los problemas económicos se afíaden las tensiones políticas entre ambas orillas del muro de Berlín, porque más que una uniticación se ha dado una anexión donde los alemanes del Este "se sienten extranjeros en su propia lierra". El temible resurgimienlo del neonazismo y el gran aluvión de inmigrantes del Este agobian la actual siluación de Alemania unilicada.

"Mala salud de hierro" es el calificalivo que los analistas aplican a la economía de los EE.UU., que se niega a recuperarse de la recesión de 1990-1991. De acuerdo a los expertos el crecimienlo económico será de $1.8 \%$ en 1992 , y se espera un $2.6 \%$ para 1993 . Un dato alarmante es el desempleo, dejando de lado los datos oficiales e integrando a quienes trabajan a liempo parcial y que ganan sueldos a nivel de pobreza, alcanzaria un tolal de 36 millones, igual al $40 \%$ de la fuerza laboral, según el Inslitulo de Política Económica de Washinglon. Hay una razón más estructural: si en los años sesenta sólo un $7 \%$ de la economía norleamericana estaba expuesla a la competencia internacional, en los anios noventa esta cifra se disparó por encima del $70 \%$. Con ocasión de las elecciones presidenciales el Time presenla una "radiografía de la crisis". Los items senalados y resumidos por el diario El País son los siguientes: La reducción de la defensa elimina uno de los grandes apoyos a la industria. La caida de los sueldos reales en un $13 \%$ con los ajustes por inflación. El délicil presupuestario, que en 1992 puede alcanzar la cifra record de 400.000 millones de dólares. Las reducciones empresariales, que para ser más competitivas y rentables han eliminado millones de puestos de trabajo, reduciéndose la creación de nuevos puestos de trabajo respecto a anos anteriores. La conlracción del crédilo ha afeclado gravemente a las empresas, sobre todo a las pequefias. En las grandes empresas, la carga de dos billones de dólares de deuda impide las inversiones de capital que la economia necesita para seguir siendo compelitiva. La quiebra de bancos y entidades de ahorro, cuyo reflolamiento se calcula en $\mathbf{5 0 0 . 0 0 0 ~ m i l l o n e s ~ d e ~ d o ́ l a r e s . ~ " E s l a ~ e c o n o m i a ~ h a ~ e s t a d o ~ e n ~}$ pie de guerra toda la vida, y eso es mucho... "La recesión mundial y la falla de perspeclivas en Europa han obstaculizado las exportaciones. En 1989 la economia mundial creció en 4.3\%: en 1992 sólo crecerá en 1.1\%. El comenlarista del Time lermina diciendo para consuelo de los lectores: "El que la economía norteamericana pueda resistir todo esto 
sin derrumbarse es una buena muestra de su fortaleza. Muchos economilas están empezando a pensar que el recurso más valioso que pueden tener los EE.UU. en la primera milad de la década es la voluntad de salir adelante". (EI Pais: 27, 10, 92; p. 4-5). Los buenos ánimos no quitan que la crisis permanece de momento.

Esta breve radiografía de dos grandes polencias mundiales es un índice de la recesión económica en el reslo de naciones desarrolladas. Al mismo tiempo que crece la incertidumbre y se apagan las expectativas optimistas que había creado el nuevo orden mundial, también el Banco Mundial disefí, columna trente a columna, un listado de hipótesis pesimistas y optimistas como escenario de "el clima para el desarrollo en el decenio de 1990". Mientras Ianto "Europa está volviendo a registrar índices de paro, inllación y délicits públicos preocupantes. Se recortan las ayudas al desarrollo, las preslaciones sociales a los trabajadores y se maquinan programas de privatización que devuelven la más cruda politica liberal a Europa" (Ibidem; p. 4).

\subsection{Europa no es el "hogar común"}

La utopia de que hablara M. Gorbachov en el capilulo sexto de Perestroka, "Europa es nuestro hogar común" tiende a desvanecerse de momento. El Esle no encuentra un hueco en el comercio mundial y pierde el ritmo en su transición a una economía de mercado. El Este descubre que quienes le habian prometido la mayor ayuda eslán perdiendo el interés de los primeros años. La República Federal Alemana está demasiado sobrecargada en sacar adelante a sus hermanos orienlales y el resto de países europeos centran su atención en las repercusiones internas que puedan derivarse del tratado de unión monetaria de Maastricht. El grupo de los siete grandes (G-7) sostienen que "el FMI debe respaldar medias rigurosas en la antigua URSS", (Boletín FMI; $27-$ 7-92) y condicionan su ayuda a la aplicación de los programas de ajuste estnuctural. (Realidad Económico-Social; 1991; pp. 673-694).

Tampoco se debe cargar toda la culpa en el opulento occidente. Si el humor soviético dice "nuestro pasado es imprevisible", mucho más lo es el luturo. Esto nos lleva a decir algo de la crisis política que sacude a Europa, entendiendo por ello una serie de revoluciones políticas, desconciertos sociales y erupciones élnicas y nacionalistas. Al desmedido centralismo sucede bruscamente el resquebrajamiento de todo el mosaico de la URSS y el bloque. Ya no existe el CAEM, ni el Paclo de Varsovia; la URSS se Iransforma en comunidad de Estados Independientes, con más de lo segundo que de lo primero. Yugoslavia se hunde en la más liera civil que la ONU no logra conlener. Sólo Checoslovaquia 
se divide pacíficamente a partir de 1993. En el coloquio de La Sorbona ya se advierle el peligro de rebrotes del nacionalismo y la xenofobia. Con la unificación alemana se teme el resurgimiento del IV ${ }^{0}$ Reich; el interrogante es: "una Europa a la alemana o una Alemania a la Europea? De hecho renace un violento grupo neonazi, adverso a los emigrantes extranjeros y crece la animosidad conira los alemanes orientales (ECA; 1991; pp. 692-694). Como contraréplica, en Europa y Medio Oriente se repilen las manifestaciones antirracistas. Los movimientos nacionales, dentro y fuera de la URSS, se ven agravados por la presencia de minorias o mayorías étnicas, resultado de las deportaciones masivas de la era estaliniana.

Europa no es, hoy por hoy, el hogar común prometido; lo es bajo otro aspecto bastante problemálico. El desempleo, la pobreza y el acoso de la guerra o luchas civiles ha generado aluviones incontrolados de refugiados sobre el occidente europeo. "Los paises del viejo continente endurecen sus leyes para impedir la avalancha de ciudadanos extranjeros. Alemania es el pais que más virulentamente está sutriendo la crisis, con un aumenlo en progresión geométrica de extranjeros". El Pais (30, 11, 92) presenta un mapa detallando el origen y destino de esta invasión de relugiados, que integran ciudadanos del Este, Medio Oriente, así como de Asia y Africa. Un mes más tarde, nuestro diario El Mundo $(2,1,93)$ traslada el mismo mapa con el mismo lítulo: "la invasión que hace temblar a Europa". La Europa de la lla guerra mundial recibió y ocupó mullilud de emigrantes en su recuperación de posiguerra; ahora la avalancha le llega cuando experimenta serios problemas de desempleo y déficil fiscal, ańadido al problema de la reconversión industrial (relo tecnológico) y de la reconversión militar a industria civil. Este mismo problema lo enirentan los EE.UU., donde los confliclos étnicos, la droga y derivados son puntos de agenda nada láciles para la nueva administración presidencial.

En el coloquio de La Sorbona se discuten otros problemas cívicopolíticos que aproximan esos paises a los nuestros. Ante lodo la desconfianza en la política y el recelo a los partidos políticos. Este temor se siente más en los representantes del bloque-Este y por cuanto se nos aplica; valga un sólo teslimonio de B. Geremek del movimiento polaco solidaridad. "La política, tal y como se ha venido practicando durante decenios, es un monopolio del poder. El resultado ha sido el rechazo en bloque de la política, del fenómeno partido polílico. El partido político en nuestros paises sigue siendo un fenómeno que se contempla con descontianza y temor. Pero, puesto que pensamos que 1989 es la apertura de este nuevo siglo ¿se abren acaso perspectivas nuevas que permitan articular la escena política? Acaso, al lado de los partidos deban apare- 
cer movimientos como el mío, Solidaridad, que es una fuerza política centrada en torno a valores éticos y no a la lucha por el poder. Se puede columbrar ahí no sólo la descontianza respecto al fenómeno de los partidos, sino acaso también uno de los signos de la evolución fulura"...Solidaridad en Polonia, Forum en Checoslovaquia, Alianza democrática en Hungria..., son, el decir de estos exposilores, movimientos nacionales espontáneamente surgidos del pueblo y, en este senlido algo más real para ellos que la socialdemocracia. De 1990 para acá lo que eslán viviendo esos países es un pluridivisionismo parlidista con la incrustación disimulada de los antiguos comunislas en la mayoría de naciones a comenzar por Rusia. Con el miedo al partido político se hace mención del problema de la corrupción, que de las capas altas se está contagiando a las capas bajas.

Un úllimo fenómeno es el resurgimiento religioso. Quien fuera por largos anos Ministro de Asuntos Exteriores de la URSS, E. Sevardnhaze, hoy presidente de la República de Georgia, se ha bautizado en la Iglesia Orlodoxa con el nombre de Georgi. El resurgimiento religioso en la Iglesia del silencio es sin duda un fenómeno positivo en cuanto luche por la unidad y el respeto muluo, los valores éticos, la aplicación de equitativa justicia... Sin embargo, en el coloquio de La Sorbona se hace una llamada de atención contra el nacionalismo religioso, que testigo la hisloria, puede generar y está generando las más agresivas confrontaciones étnicas tan antiguas como el Corán o la Biblia. Sobre el fenómeno religioso hicimos antes una breve referencia y la volveremos a hacer por la importancia que tiene hoy y ahora de cara a los Acuerdos de Paz.

Al concentrarnos en la macroencuesla europea y en el coloquio de La Sorbona, no hemos mencionado los cońlictos del Medio-Oriente, la guerra ganada y perdida con Irak, la desolación y las hambrunas africanas. De los dragones sudasiáticos y del temible competidor japonés se habla con admiración, y cada vez se va a hablar más del conlinente chino que surge sólidamente con el difícil equilibrio de "libertad económica si, libertad política no". Mundo distinto el mismo mundo y por to tanto distintas visiones sobre el mismo Es el momento adecuado para releer el capítulo tercero de Perestroika: "Cómo vemos el mundo actual? Y lo vemos interdependiente e interrelacionado, donde no se pueden lograr los intereses de unos sin salvar los intereses de los demás. Por lo lanto discutamos los problemas con espírilu de cooperación más que de animosidad. Todos los países tienen sus problemas, pero los países en desarrollo los lienen cien veces más que los otros Estados y eso debe ser tomado en consideración" (p. 158). No se puede en dos líneas cambiar nuestro planeta, pero si es posible esbozar dos lineamienios de 
acuerdo a los resullados de la comentada macroencuesta.

\subsection{Conservadores en lo económico}

Esta expresión liene varios signilicados históricos y no la podemos reducir a la superticial alternaliva de plan-mercado. A lo largo del siglo$X X$ más que conservadores hemos sido depredadores del mundo y de sus recursos físicos, tanlo en virtud de la propiedad privada como de la propiedad estatal, mostrando que ni la una ni la otra han sido propiedad social. Los ecologistas nos dicen, y con toda razón, que el problema actual no es producir más, sino producir distinto y con mayor sobriedad. De 1970 para acá varias amistades y distinlas guerras han surgido, no de la defensa de los derechos humanos, sino del instinto de dominación y depredación de los recursos naturales. Por estos recursos físicos se han peleado las naciones y con las guerras se ha logrado reducir más los ya escasos recursos naturales; cada vez son menos los bienes libres y hasta los letreros publicilarios interrumpen la conlemplación de la naturaleza. Con la ecología hay que reorientar la economía en cuanto ciencia de la administración de los bienes escasos. Pero no hay ciencia sino hay toma de conciencia de que los recursos hoy disponibles no permiten establecer como ideal de vida el consumismo-derrochismo de la sociedad primermundista. El pecado original de nuestras regiones es ambicionar parámetros de bienestar que en el mediano plazo nos empobrecen. La economia de mercado y el efecto-imitación tienen su arte y su parte en esta degradación económica.

Conservadores en lo económico significa el reto de la revolución tecnológica. La tecnologla ha ayudado a resolver el problema de la escasez, aunque no en forma equitativa y hasla el momento no ha resuelto el problema ecológico; quizás lo ha multiplicado.'Bienhechora y necesaria desde un punlo de vista, también es agente de perturbaciones y discriminaciones sociales. A la tecnologia se le ha descrito como un proceso de creación destructiva: el innovador desplaza al conservador. Los primeros obreros de la revolución industrial rompian las máquinas porque ellas los destruian-desplazaban a ellos. Hoy día la revolución tecnológica obliga a hacer grandes gastos en la reeducación profesional de cuellos blancos y trabajadores manuales en los mismos paises industrializados. Parte del actual desempleo se debe a la revolución tecnológica; tanto la antigua URSS como los EE.UU. enfrentan este problema.

Administradores de empresa y economistas debemos leer "La ventaja competiliva de las naciones" de Michael E. Porter para orientar en lo posible nuestra reconversión indusirial y nuestra Ley de Ciencia y Tec- 
nología. Este es un reto ineludible para nosotros luego de la parálisis y de la destrucción de postguerra: una economia de empresa en una economía de sobriedad. Pero como lo han comentado tanlos y en tan diferentes publicaciones no podemos adquirir verdadera ciencia y tecnologia socialmente si no asentamos las bases de una amplia educación, saludnutrición popular. Una tecnología imporlada y capitalística, desconeclada de un impulso masivo a los programas de educación, probablemenle generará mayores discriminaciones sociales. El borrador de ley de ciencia y tecnología, en trámites de aprobación, resuma una inspiración neoliberal, donde se concentrarían los esluerzos y avances científicos de universidades y otras instituciones investigadoras, canalizadas lodas ellas al servicio de la lípica empresa privada. Es de esperar que la Asamblea Legislativa presle oídos a malizaciones presenladas.

El Dr. Richard Jakob, en su articulo sobre la economia social de mercado, traslada unas palabras del Banco Mundial extraidas de los Informes de Desarrollo Mundial de 1990-1991. "Es obvio aun para quienes no son economistas, que la economía de un país, en el cual grandes partes de la población padecen de hambre, tienen mala salud y poca educación, a la larga no puede crecer. Diversos estudios han determinado que la educación es la variable que más influye en la desigualdad en la distribución del ingreso. Las inversiones en educación, salud y nulrición -si están bien concebidas y aplicadas- pueden mejorar la distribución y, al mismo tiempo promover el desarrollo por otros medios... El crecimiento económico requiere, sin lugar a dudas, inversiones para aumentar el capilal lísico. Pero, en primer lugar, el crecimiento económico es producido por hombres produclivos y molivados. Por eso la satisfacción de las necesidades básicas, el alaque direclo contra la pobreza, las inversiones en el capilal humano, no son un despillarro social, sino condiciones necesarias para el crecimiento duradero"...7

También FUSADES, en su Informe Económico Sermanal, dedicado al tema de el desarrollo para conservar la paz como tarea de todos, hace la misma recomendación desde su propio enfoque: "Es de suma importancia recalcar que para que todas las personas puedan aprovechar las oportunidades y beneficios que ofrece una economía de mercado, el Eslado debe concentrar su inversión en la formación de capital humano. La inversión en educación tiene una importancia económica y estratégica fundarnental. Primero, porque el proceso de reconversión económica

7. Jakob R.: "Política social en la economia social de mercado. "Qué significa "social" en el concepto de economía Social de Mercado?". Contribuciones; $3 /$ 92; p. $91-92$. 
demanda contar con un recurso humano calificado. Segundo, porque la educación es el instrumento que permile forlalecer la democracia de forma efectiva y permanente. Tercero, porque la educación contribuye a una verdadera equidad de oportunidades, donde lodas las personas pueden desarrollarse y superarse. Por lodo eso, mejorar la calidad del capital humano de nuestro país es una inversión impostergable para el mantenimiento de una paz duradera". ( $N^{2} 51 ; 16-12=92$ ).

Conservadores en lo económico significa lo contrario de ser conservador-dogmático. Es claro que en la macroencuesta europea y en los documentos antes cilados hay un rechazo al dogmatismo de los socialismos reales, a la modalidad de la planificación centralista soviética que esterilizó los aportes de grandes economislas e ingenieros, despresligiando el desarrollo de una leoría económica con las acusaciones de revisionismo y de ambición política, y derivando a una descomposición del sistema de precios, derroche de recursos, descuido de la calidad o valor de uso de la producción civil, crecienle déficil fiscal, desorganización del sistema monetario y transformando el comercio intrasocialisla (CAEM) en un régimen de trueque asentado en un rublo transferible pero no convertible. Una descripción de los resultados y de las reformas propuestas podemos encontrarla en el informe de $M$. Gorbachov al Pleno del Partido (junio, 1987) o en el programa de A. Aganbegian para la reestrucluración económica. (ECA, 1991; pp. 704709). Olro género de dogmatismo es el de quienes reducen todo el proceso económico a las leyes o reglas de los juegos. EI Dr. Richard Jakob critica la posición liberal del Dr. Friedrich A.von Hayek, para quien conceplos como "Juslicia Social, Estado Social de Derecho, o Economia Social de Mercado carecen completamente de sentido. El sostiene que los resultados del proceso de mercado, por definición, no pueden ser injustos si las reglas de la competencia son justas. Las competencias de los mercados se ve como un juego. En realidad el proceso de mercado corresponde perfectamente a la definición que da el Diccionario de Oxford de "juego": es una competencia de acuerdo a reglas que se decide por habilidad superior, por tener más tuerza o también por suerte. Según esto, asi como es de ilógico calificar de justo o injusto el resultado de un partido de lútbol si los equipos han jugado limpio y contorme a las reglas, igualmenle ilógico es decir que los resultados del proceso de mercados son juslos o injustos, si todos los participantes han actuado de acuerdo a reglas de compelencia juslas. La juslicia sólo liene sentido en relación a las actuaciones humanas y no a una situación "... Hasta aqui la posición de F. A. von Hayek, que R. Jakob critica desde la lilosolia de una economia social de mercado, "a la alemana"; Una posición tan unilaleral como esla no va de acuerdo con el conceplo 
de la Ecnomía Social de Mercado. La Economía, que está llamada a crear las bases materiales para una vida humana digna, no puede ser reducida a un juego en los mercados y reglas leales de competencia. Cuando se pierde un juego de lútbol no es una cueslión existencial. En relación con la economía, sin embargo, casi para todos los hombres se Irata de cosas existenciales. Una posición tan cínica y peyorativa del ser humano de reducir la economía a un juego, sólo la puede adoplar alguien que eslá alejado de todos los problemas materiales y para quien no liene importancia salir un poco mejor o un poco peor en el "juego del mercado". Los liberales insultan a los pobres con su arrogancia queriéndoles hacer creer que no tiene suliciente éxito en el "juego del mercado" porque son muy tontos o porque simplemente han lenido mala suerle por su origen. Según esla posición liberal de von Hayek, lo único que puede hacer por los pobres es evilar que se mueran de hambre dándoles limosnas. Además el modelo de "juego de mercado" tampoco es correcio, porque un juego, aun cuando hay reglas limpias y juslas, sólo tiene sentido cuando todos los participantes tienen condiciones de partida similares y existe para lodos oporlunidad de ganar..." Esle arliculo es plenamente recomendable para el año preelecloral.

Conservadores en lo económico significa que hay que respetar las grandes normas y las grandes limitaciones que nos impone la economia. El deterioro ecológico universalizado muestra que ninguno de los modelos ha respetado las limitaciones que nos impone la economia. Los enormes gastos armamentísticos trenle a la extrema pobreza de los dos lercios del mundo signilica que ninguno de los sistemas ha observado las grandes normas de la economia. El hecho de que las más grandes naciones tengan los más grandes déficits estalales (en buena parte déficils de guerra, como el nuestro) significa que ni los sectores públicos ni los privados han hecho buena economia. Cuando los tres grandes flujos internacionales son el comercio de armas, el trálico de la droga y el creciente pago de la deuda exlerna, algo anda mal en el orden económico internacional. El hecho de que siga dominando la incertidumbre y la inseguridad, incluso en los paises desarrollados, es un signo de que nuestra economía sigue siendo insegura e incierta. De cara a las economias del Este llegamos a la conclusión de que el plan requiere de la orientación y del control del mercado. De cara a las economias del Oeste decimos que los mercados sectoriales requieren de la orientación e integración de un plan que marque los objelivos sociales del medianolargo plazo. Conservadores en lo económico significa no alerrarse a la letra y a las fórmulas de las teorías, sino evaluarlas y aceptarlas de

8. Ibidem; pp. 67-88 
acuerdo a los resultados económicos y sociales. Signilica la virlud de admitir los errores, de dialogar y concertar propuestas, de estar abiertos a olras lecturas de la realidad. Significa lundamentalmente caer en la cuenta de que además de lo económico existen los derechos humanos, la juslicia, el miedo y la inseguridad, la religión y la corrupción, la política y las clases sociales ..., y lantas otras cosas que no entran en la contabilidad del producto nacional. Por ello, ser conservadores en lo económico requiere otra precondición.

\subsection{Soclallsias en lo demás}

Cuando decimos "en lo demás" decimos algo muy amplio, no solo porque abarca muchas áreas del mundo social, sino porque supone nuevas ideas. Sin embargo no separamos lo económico de "lo demás", porque la economía será social o antisocial de acuerdo al resto de las esleras sociales, entre las cuales una es la economia. Si to politico, lo militar, la justicia, la práctica religiosa, el respeto a los derechos humanos, la corrupción, las clases sociales..., si todo ello es antisocial dificilmente jugarán bien las reglas del juego del mercado con igualdad de oportunidades para todos. Socialistas en lo demás signilica una cosa tan sencilla y tan dificil como el tomar conciencia de que vivimos en una sociedad nacional e internacional donde el bienestar de los unos eslá relacionado y depende del bienestar de los demás. El neoliberalismo tiene una visión globalizanle del mundo; pero esa visión parece emanar desde la balanza de pagos, es decir cómo utitizo el resto del mundo para mi propio crecimiento. Es una visión competiliva donde los grandes se unen para ser más luerles y donde se práctica el "caso por caso" con los más débiles. A nivel nacional los portaestandartes de la doctrina neoliberal expresan sus propósitos de defender a los débiles y erradicar el problema de la pobreza, pero de acuerdo al principio de que los mercados son la panacea para todos los problemas sociales. El Inlorme Económico Semanal de FUSADES antes citado ( $N^{2} 51$; 16-12-92), tiene el mérito de inlegrar en una sola página el problema económico con baslantes problemas sociales, que pretende combinar el conversadores en to económico y sociales en los demás, pero siempre a partir de 10 primero. Los mismos enunciados tienen distinta traducción cuando se expresan en abstracto, como ideal, que cuando se quieren aplicar a una realidad concreta como es la nuestra. Sin querer manipular el informe trasladamos algunos párralos que quedan como agenda de reflexión. "EI crecimiento económico es una condición necesaria para alcanzar el bienestar social. La pobreza y el desempleo no son fenómenos que puedan resolverse con políticas redistributivas, ya que éstas tienden a fomenlar actiludes como la dependencia y el paternalismo, que limila la 
creatividad de los individuos para aprovechar oportunidades y conlribuir al desarrollo. Para superar los problemas del subdesarrollo deben enfrentarse seriamente los desalios de la producción y la eficiencia de lodos los sectores... Los sindicalos deben entender que para alcanzar el bienestar de sus afiliados es necesario fomentar una mayor identificación de los empleados con sus empresas. Los Irabajadores deben aceptar su responsabilidad en el mejoramiento de sus empresas y los empresarios deben estorzarse por capacitar a sus empleados para que sean más produclivos... En este sentido (el eslablecimienlo de un verdadero eslado de derecho en la sociedad) es pertinente sefialar, primero, que para alcanzar niveles sostenidos y crecientes de bieneslar se requiere de un marco jurídico que asegure las liberlades individuales. En segundo lugar, se deben respelar los derechos de propiedad, ya que nadie estará incentivado a invertir en esle pais si no tiene la cerleza que su derecho de propiedad será respetado. En tercer lugar, es crucial fortalecer el sistema judicial para hacer valer el derecho a vivir en paz, el derecho a la libertad de elegir y el derecho a la propiedad..."

Se hace referencia a los articulos 101 y 102 de la Constilución "que responsabiliza al estado de promover el desarrollo económico y social mediante el incremento de la producción, la productividad y la racional utilización de los recursos y... de fomentar y proteger la iniciativa privada para acrecentar la riqueza nacional y asegurar los beneficios al mayor número de habitantes"... Se intercale en el informe el párralo antes citado sobre la necesidad de mejorar la calidad del capital humano, y se termina con una recomendación a los partidos políticos. "Ahora contamos con una democracia que estuvo ausente en el pasado y cuya falta dio origen a posiciones radicales y destructivas: $\gamma$ Sin embargo, el funcionamienlo de la democracia para alcanzar la paz y el desarrollo implica que deban hacerse a un lado los intereses partidislas y buscar con seriedad el bien del pueblo. La paz exige la discusión de soluciones serias a nuestros problemas económicos y sociales $y$, ante lodo exige de la población un decidido apoyo a la verdad y un rechazo a la demagogia y al populismo:yMás aún todos debemos comprender que nuestro problema no es un problema de distribución, sino de producción. No podemos producir sin estar educados, ser eficientes y aprender a competir. Es importante reconocer que nuestra incipiente democracia requiere de una sólida economía para mejorar el bienestar de la población. erradicar la pobreza y conquistar el desarrollo para conservar la anhelada paz que tenemos el gusto de celebrar".

No es el propósito de entrar aquí a un comentario o discución sobre el enfoque del presente informe, que en buena parte se hizo en anterior 
publicación con el título de "El neoliberalismo no es un dogma de fe", en el $N^{2} 29$ de esta misma revista. Como a lo largo de 1993 se seguirán discutiendo alternativas de solución a nuestros problemas económicos y sociales, basle seguir un párralo más del Dr. R. Jakob comentando el modelo del juego del mercado y la necesidad de complementarlo con la política social. "Esto aplicado a la economia significa que los resultados u oportunidades de ganar en el "juego del mercado" no depende solamente de la limpieza o justicia de las reglas de competencia, sino lambién de las condiciones de partida, sobre todo, de la distribución de los ingresos y del capilal. Si se supone que el juego del mercado debe tener un sentido debe existir una distribución de los ingresos y del capilal que dé oportunidades de éxito a la mayor cantidad posible de personas. Lograr esta distribución es larea importante de la política social. Pero aún cuando en un país se pudiera llegar a realizar una distribución completamente justa y unas reglas de competencia completamente justas para los mercados, la politica social no se volveria superflua Aún al darse esta condición de partida ideal, siempre habría personas que, por esfuerzo, talento o suerte, tendrian más éxilo que olras, o sea que obtendrian un ingreso mayor que otras. Esto, en principio, no es ningún problema y corresponde a los crilerios de la juslicia por mérito. Sin embargo, se vuelve peligroso cuando los ingresos más altos se convierten en poder económico y político, pues según lodas las experiencias, éste se uliliza para cambiar las "reglas del juego" en beneficio de los poderosos. El Estado cae bajo su control y lo utilizan para conservar sus privilegios económicos. De ahi que la función de la política social de crear la juslicia social no puede ser un acto único, sino un acto permanente"o

Lo que olvida el informe de FUSADES es que nuestro punto de partida no es el ideal de igualdad de oportunidades, sino la siluación de concentración del poder económico y político y la supeditación del Eslado en beneficio de los poderosos. En esta situación de partida la mercadocracia no genera la democracia, el desarrollo de la mayoría del pueblo ni la paz "que todos tenemos el guslo de celebrar". Si tanto se ha luchado por los acuerdos de paz, si tanlo se eslán irenando los acuerdos de paz, si hay una resislencia a que se descubra la verdad, si quien debiera manifestarla se resiste y se niega, incluso ante las presiones de las Naciones Unidas, todo esto quiere decir que no sólo hay predominio en lo económico sino también en las grandes determinaciones politicas. El gran problema social es el ocultamiento global de la verdad: la verdad en lo político, la verdad en la administración de la

9. Jakob R. ibidem; p. 88. 
justicia, la verdad en lo económico, la verdad en los partidos políticos, la verdad en los medios de comunicación social, la verdad en la reconsirucción nacional, la verdad en los partidos políticos, la verdad incluso hasta en la calidad de la producción empresarial, por un lado y por el otro en la publicidad y en los informes gubernamentales. Por eso podemos resumir el ideal de ser socialistas en lo demás en el simple compromiso de buscar la verdad y decir la verdad.

\section{1993: año preelectoral ¿de qué y de qulén?}

El Papa Juan Pablo-11\%, en su mensaje de primero de enero 1993, da una respuesta concreta: "Si quieres la paz sal al encuentro del pobre". Su punto de partida es una mirada al mundo actual: "Se constata y se hace cada vez más grave en el mundo olra seria amenaza para la paz; muchas personas, poblaciones enleras viven hoy en condiciones de extrema pobreza. Lá desigualdad entre ricos y pobres se ha hecho más evidente incluso en las naciones más desarrolladas económicamente. Se trata de un problema que se planlea a la conciencia de la humanidad pueslo que las condiciones en que se encuentran un gran número de personas son tales que ofenden su dignidad innata y comprometen, por consiguiente el auténtico y armónico progreso de la comunidad mundial" (p.4). A continuación Juan Pablo $\|^{9}$ nos remite a la recienle conferencia del Episcopado Latinoamericano, celebrada en Sanlo Domingo el pasado mes de oclubre. "Los obispos han recordado la gran misión que debe coordinar los esfuerzos de todos: delender la dignidad de la persona, comprometerse en una distribución equilaliva de los bienes, promover la manera armónica y solidaria una sociedad donde cada uno se sienta acogido y amado. Estos son como se puede ver los presupuestos imprescindibles para construir la verdadera paz. En eleclo, decir paz es decir mucho más que la simple ausencia de guerras; es pedir una situación de auténtico respelo a la dignidad y los derechos de cada ser humano que le permila realizarse en plenilud. La explolación de los débiles, las preocupanles zonas de miseria y las desigualdades sociales constituyen otros tantos obsláculos y rémoras para que se produzcan las condiciones estables para una auténtica paz. (p.4-5).

Digamos que estas palabras del Papa encajan con los acápiles de los Acuerdos de Paz y con el tenor de los discursos de México y San Salvador. Por ello 1993 es un año eslralégico de acuerdo a que se conserven o se desmoronen las posiciones sostenidas en 1992.'Los Acuerdos de Paz han propiciado una disposición para ponerse "de acuerdo" para mantener el diálogo, para encontrar las mejores soluciones a lo que aún queda por cumplir; no lodo ha sido agua corriente, 
pero es mucho lo que se ha avanzado en esla dirección. COPAZ es un símbolo de integración partidaria, de acuerdos dificiles entre distintos, que ha repercutido en la compostura de la misma Asamblea Legislativa. EI Foro de concertación Económica-Social se eslá convirtiendo más bien en un presagio de lo contrario. $Y$ lo contrario es que, en un entorno preelectoral, se puede pasar de la interpartidaria a la conirapartidaria. No sólo que los partidos se enirentan entre sí, sino que en la búsqueda del poder tienden a partirse dentro de sí mismos. El peligro es que el partidismo o divisionismo se convierla en una rémora o relraso de lo ganado en 1992. No decimos esto porque esperamos que asi suceda sino para desear que ojalá no suceda.

y. En este proceso de transición parlamentaria los Acuerdos de Paz han sido el semillero del diálogo-concerlación y eslán creando una cullura de la verdad. Se han tocado temas que antes no se podian mencionar, y por ello son tan fuertes las resistencias a que aparezca toda la verdad. Hay lugar a un optimismo realista viendo la siluación desde fuera y desde dentrosEl Salvador ha sido un centro de atención y de admiración internacional, pudiendo ponerse de ejemplo para naciones cercanas y más lejanas. El interés mostrado por el grupo de apoyo, el mismo cambio presidencial en los EE.UU. pueden mover vientos más democrálicos. Al inlerior del país crece el número de quienes vigilarán y lucharán por el cumplimiento de los acuerdos, así como crece la oposición a quienes ocullan la verdad. Aunque trislemente han aparecido divergencias, que ojalá se hagan convergencias, es alentador y tranquilizante lo que dicen y proponen los descendientes de las montańas. Sus propuestas se hacen "con espiritu de cooperación más que de animosidad". La animosidad más bien brota de quienes se silúan en el otro extremo del péndulo y en algún diario matutino./Afíadamos la presencia de terceras fuerzas sociales, el apoyo de las iglesias comprometidas, de algunas universidades e instituciones de investigación $y$, por supuesto, del verdadero pueblo que es el pueblo verdadero.

A nuestro mundo de 1993 Juan Pablo-II', y sus asesores, le presentan un esquema de modelo económico social un lanio dirícil de enlallar en los principios neoliberales. La parle quinla del mensaje se litula: "Es. piritu de pobreza como fuente de paz" y se nos hace la siguiente propuesla. "En los paises industrializados la gente eslá dominada hoy por el ansia frenética de poseer bienes materialesł La sociedad de consumo pone todavia más de relieve la distancia que separa a los ricos y pobres, y la atanosa búsqueda de bienestar impide ver las necesidades de los demás. Para promover el bieneslar social, cultural, espirilual e incluso económico de cada miembro de la sociedad es pues imprescindible 
frenar el consumo inmoderado de bienes materiales y contener la avalancha de las necesidades artificiales. La moderación y la sencillez deben llegar a ser los crilerios de nuestra vida colidiana. La canlidad de bienes consumidos por una reducidísima parte de la población mundial produce una demanda excesiva respecto a los recursos disponibles, La reducción de la demanda constiluye un primer paso para aliviar la pobreza, si esto va acompañado de esfuerzos elicaces que aseguren un ajusta distribución de la riqueza mundial" (pp. 12-13). Lo que el Papa aplica a nivel mundial nosolros lo adoptamos a nivel nacional.

Sería impertinente lomar estas palabras como recomendaciones ascéticas y monacales. Si ensamblamos las partes de este mensaje que enlazan paz y lucha conlra la pobreza, dignidad de la persona y solidaridad social, lo que aqui se nos presenta es un esbozo de modelo económico para nuestra siuuación de postguerra, de reconstrucción nacional con escasos recursos y ecologia deteriorada, de consumo inmoderado por una reducida parte de la población. Eslos criterios de moderación y sencillez se están traduciendo en propuestas de reorientación económica, sea bajo forma de nueva economía popular, como integración de las necesidades básicas en la reactivación económica, las mismas organizaciones comunitarias o cooperativislas, y de una manera general como la integración del desarrollo desde dentro en el modelo de crecimiento hacia fuera-- Muchas veces se ha repelido que una recuperación de post-guerra, en un enlorno de escasos recursos y abundanle pobreza, necesita renunciar a la producción e imporlación de bienes superlluos, de ostentación y de lujo, que no activan seclores produclivos internos, malversan las escasas divisas y desentonen socialmente cuando la mayoria carece de los bienes-servicios elementales ¿ Económica y socialmente no es lo más apropiado que, a la par de un Plan de Reconsirucción Nacional que parcialmente suministra la más imprescindible inlraesIructura tísica y social a la llamada zona conflictiva, el modelo de libre mercado propicie amplias zonas rosas de ostentación. No es esle el mejor condimento para la paz. La sobriedad y la moderación no son una sobrecarga para el delerioro ecológico, favorecen el uso de recursos nacionales y propician la creación de una tecnología manual más adecuada a nuestras disponibilidades de capilal y trabajo. Más difícil de entender en nuestro entorno consumista es la "aurea mediocrilas" de los filósolos latinos o de los libros bíblicos: "no me des ni poco ni mucho, sino lo necesario para vivir":-

La moderación y sencillez del mensaje papal se lundamenta en otras razones económicas que han sido muy debatidas enire nosotros en los tres últimos años. En la página 9 del mensaje el Papa introduce la presentación de tres problemas particularmente inquielantes y que alec- 
Ian a los pobres: la deuda externa, la droga y las corrientes migratorias masivas. "Ante todo el problema de la Deuda Externa que, para algunos paises y en ellos para los seclores menos pudientes, sigue siendo un peso insoportable... ¿ No son quizás los sectores más pobres de dichos países los que tienen que sostener trecuentemente la carga mayor de la devolución?... Las condiciones de la devolución tolal o parcial deben ser revisadas, buscando soluciones delinitivas que permilan atrontar plenamente las graves consecuencias sociales de los programas de ajuste. Además será necesario actuar sobre las causas del endeudamienlo, condicionando las concesiones de las ayudas a que los gobiernos asuman el compromiso concrelo de reducir gaslos excesivos o inútiles - se piensa particularmente en los gaslos para armamenlo-y garanlizar que las subversiones lieguen efeclivamente a las poblaciones necesiladas" (. 9).

Aplicamos brevemente estas reflexiones a nuestro pais. Como telón de tondo la deuda externa, directa y garantizada, del sector público expresada en millones de colones ha evolucionado en la forma siguiente: 70 (1962); 223 (1970); 707 (1980); 6.272 (ajuste por cambio, 1986); 12.013 (1990); 14.058 (1991). ¿Cuáles han sido las grandes causas de esle endeudamiento estatal? En las décadas sesenta y setenta serán los grandes gastos en intraestructura física la sumatoria de exenciones y subvenciones a la industria naciente. EI Plan de Desarrollo Económico y Social 1973-1977 comenla: "Así mismo las obras de infraestructura ejecutadas por el Eslado, particularmente las carreras, han elevado considerablemente el valor de los bienes adyacentes, sin que tal siluación se manifiesle en los ingresos fiscales. Esla siluación además de promover una verdadera especulación no permile que el Estado recupere el gaslo de sus inversiones. Por lo general esos bienes raices perlenecen a personas de altos ingresos. En esle campo se recomienda la creación de un impuesto sobre la plusvalia de los bienes raíces". (p. 93) Baste agregar que muchos de estos bienes raices los revaluaron los duefios en 1980 al decretarse la reforma agraria. Llegados a la década de los ochenta, a la adversa coyunlura internacional y a las politicas monetarias de la administración-Reagan que elevaron los tipos de interés y revaluaron el dólar, se agrega como causa principal los gaslos del conflicto armado. Quienes desde dentro y desde fuera, y no ciertamente el verdadero pueblo, votaron e impulsaron la guerra, en realidad eslaban votando por el délicit fiscal y el incremento de la deuda externa. El resultado queda reflejado en la serie de millones de colones endeudados. Como réplica a las causales de la deuda externa tenemos la estruclura regresiva de los impueslos: la serie de mediano-largo plazo distribuye los gravaménes tributarios en un tercio de impuestos directos y 
dos tercios indirectos, distribución contradictoria a la que lipifica la apropiación de la renta-capital. Esta regresividad se ha acentuado con las reformas liscales emanadas del programa del ajuste eslructural, sobre lo cual se ha derramado mucha tinta y se seguirá discutiendo en la fase preelectoral. Si a la carga impositiva le agregamos el deterioro que la inflación ejerce sobre los ingresos relativamente lijos, son los sectores mayorilarios quienes vienen cargando con las consecuencias adversas de nuestra evolución económica. Los datos del Indice de Precios al Consumidor fundarnentan los reclamos del Comilé de Delensa del Consumidor. EI IPC año base 1972-100 ya se habia elevado a índice 200 en 1978; corriendo la escala a 1978-100, el IPC de octubre-1992 asciende a 1.001.29 y para los alimentos a 1.290.62. A partir del mes de septiembre las protestas de las clases laborales se han incremenlado a medida que aparece cada vez más claro que las medidas del ajuste estruclural favorecen a los que relativamenle lienen más, sobrecargando a los que relativamente siempre han lenido menos. Para 1993 las dos grandes partidas del erario público sigue siendo el pago de la deuda $(20 \%$ del presupuesto) y los gasios de defensa-seguridad, objelo de aguda controversia al iniciarse el nuevo año.

Otro problema que menciona el mensaje papal y que encaja en estas reflexiones es de las "corrientes migratorias masivas hacia paises más afortunados". Ahora miramos la migración desde la dirección contraria: las masivas remesas de emigrante, bien llamados "los pobre-dólares". Aunque no se dispongan de estadísticas precisas y las cifras reales promedien los cálculos del P. Segundo Montes, CENITEC y el BCR, no es exagerado afirmar que el monto de eslas remesas dejaron alrás los $\$ 500$ millones y seguramenle los $\$ 700$ millones en los últimos años, superando el valor de las exporlaciones tradicionales en declive y aun el de las exportaciones tolales. Mientras que en la década de 1980 la luga de capital dejaba desnacionalizada la banca inlerna, entonces y más ahora el crecienle flujo de pobre-dólares ha aliviado la balanza de pagos, el tipo de cambio y sigue ayudando a cumplir con los requerimientos del ajuste eslructural. La pregunta es: ¿qué eslá haciendo el modelo y el programa de ajuste estruclural por ayudar a los pobres que eslán salvando al modelo y al ajuste estruclural? Porque la paz no nace del equilibrio macroeconómico de la balanza de pagos sino de la solidaridad social en la equidistribución del trabajo, del sacrilicio en el consumo y de los gravámenes públicos en periodo de reconstrucción. La moderación y la sencillez no son recomendaciones monacales, asi como la consigna "sal al encuentro del pobre" signilica toda una remodelación económica desde una visión neosocialista. Cuando se enliende el signilicado humano y cristiano, la palabra no debe asuslar. 
Desde este mensaje papal para 1993 cobran sentido aquellas palabras de $M$. Gorbachov que nos sirvieron como introducción a este comentario: "el socialismo democrático es una idea que extrae energia de muchos hallazgos del cristianismo y de otras tendencias filosóficas". En esle sentido nos alegra encontrar en la publicación cilada de Joaquín Villalobos una defensa y una necesidad de fundamentar el nuevo periodo nacional en una inspiración religiosa cristiana. Luego de citar la doctrina social de la iglesia católica como una de las vertientes de inspiración democrática, J. Villalobos ańade: "Se necesita fortalecer la religiosidad nacional y el ecumenismo, asumiendo la larea de la reconciliación nacional desde las bases, buscando el desarrollo de una conciencia liberadora para las nuevas condiciones de paz. El pensamiento cristiano, que estuvo presenle en toda la lucha, puede $y$ debe asumir las bases élicas de la nueva forma de hacer politica y servir a la sociedad, poniendo el humanismo cristiano como base élica de principios que regule los requerimientos del pragmatismo en el quehacer polílico". En líneas anteriores de la misma página hace una observación de la religiosidad verdadera a que se refiere". Las condiciones han cambiado; los sectores crislianos necesitan renovarse y poner alención, ya que las religiones inlormales están llenando el vacio de la religiosidad en su sentido más estriclo con propósitos muchas veces alienantes y conlormistas, y por otro lado hay sectores crislianos sumamente radicalizados que necesitan adaplarse a la nueva siluación. No se trata de instrumentalizar la religión como lo hacen los falsos predicadores o los que mientras promovian la persecución y el asesinato de religiosos, fomentaban el conformismo con religiones informales" (p. 62-63).

\section{A modo de conclusión}

Llegamos a un punlo donde la comparación de lodos los testimonios citados nos lleva a deducir una convergencia de principios en los movimientos socialistas: $\mathrm{En}$ el presente siglo, especialmente en las tres ülimas décadas, se ha evolucionado desde la confrontación a la confluencia de dichos movimientos. La Historia del Pensamiento Socialista de G.D.H. Cole describe a profundidad las tensiones a muerte, los calificalivos de "socialtraidores" y de "antidemocrálicos" que volaban de un lado al olro de las trincheras ideológicas. La hisloria y los problemas del siglo- XX, no resueltos por ninguno de los modelos y sistemas, han gestado una neo-teoria brevemente esbozada en la parte introductoria. La vuella al mundo, en cinco páginas, nos descubre que junto a la actual recesión económica se da una crisis de valores y problemas civico-sociales. "Conservadores en lo económico, socialistas en los demás" recoge el doble cueslionamiento mundial, que para nosotros se Iraduce 
en la reconsirucción económica y en los Acuerdos de Paz.. Las encíclicas y el mensaje papal, que habla de dignidad de la persona, de solidaridad social, de moderación y sencillez económica, se pronuncia por un modelo social cristiano, muy en consonancia con los principios del socialismo democrático. Por esta razón el neo-socialismo pide la palabra en el ańo preelectoral de 1993: ¿a favor de qué y de quiénes debemos votar? 